\title{
High Precision Temperature Controlling AGPase in Wheat Affecting Yield and Quality Traits
}

\author{
R. BAtra ${ }^{1 *}$, P. Kumar ${ }^{2}$, M.R. JANGRA ${ }^{1}$, N. PASSRIChA ${ }^{3}$ and V.K. SikKA ${ }^{1}$ \\ ${ }^{1}$ Molecular Biology, Biotechnology and Bioinformatics, CCS Haryana Agricultural University, \\ Hisar-125 004, India \\ ${ }^{2}$ Plant Quarantine Division, ICAR - National Bureau of Plant Genetic Resources, New Delhi-110 012 , India \\ ${ }^{3}$ Plant Molecular Biology, International Centre for Genetic Engineering and Biotechnology, \\ New Delhi-110 067, India \\ (Received 24 August 2016; Accepted 21 March 2017; \\ Communicated by S. Gottwald)
}

\begin{abstract}
Adenosine diphosphate glucose pyrophosphorylase (AGPase) is the rate limiting enzyme of starch biosynthesis that directly affects the wheat productivity. AGPase and grain growth rate (GGR) discerned to be following strict temperature regimen in wheat disomic chromosome substitution (DCS) lines. The first half of grain filling period had chromosome 1B and $2 \mathrm{D}$ as prominent players, whereas second half was mainly controlled by chromosomes $6 \mathrm{~A}$ and 5B. Chromosome 2D had major contribution towards yield in a specific temperature range of $23 \pm 1.5^{\circ} \mathrm{C}$ during initial stages of grain filling which can serve as an effective early screening tool for terminal heat tolerance in wheat. Chromosome 2D with highest amylose content can also be utilized to produce low digestibility flour. Grain yield was found to be significantly associated with spikes/plant, grains/spike, grain weight/spike and plant biomass. Further, path analysis indicated that though grains/spike had less direct effect on grain yield but its indirect impact on grain yield via AGPase-21 activity was high.
\end{abstract}

Keywords: AGPase, DCS lines, wheat yield, temperature, grain growth rate

\section{Introduction}

Starch is the major component of seed of cereal crops, accounting for $65-75 \%$ of the available carbohydrates (Cornell 2003). ADP glucose pyrophosphorylase (AGPase) catalyses the first key and rate-limiting step in starch biosynthesis. Overexpression of modified forms of AGPase not only reported to enhance rate of starch synthesis but also grain yield (Stark et al. 1992; Li et al. 2011; Hannah et al. 2012). Deregulation of AGPase activity by null mutation leading to increase in seed yield in maize (Giroux et al. 1996; Cross et al. 2004) gives major evidence to support the idea that AGPase is really a rate-limiting enzyme in starch synthesis.

However, its activity is severely inhibited by heat stress, which contribute to significant decline in crop yield by disturbing the grain filling duration in plants around the world (Boehlein et al. 2008; Dias and Lidon 2009; for a review see Saripalli and Gupta 2015). Various plant species have evolved different mechanisms at physiological and

*Corresponding author; E-mail: ritu.biotech24@gmail.com 
molecular level to cope with heat stress. Among these, high grain weight in heat stress may be a criterion for selection of cultivars for heat tolerance (Dias and Lidon 2009). Further, it is also important to know the location of the determinants of the vital yield component attributes which are responsible for sustained improvement efforts. Wheat scientists have exploited cytogenetic approaches like disomic chromosome substitution (DCS) lines for locating genes on chromosomes unambiguously (Joshi et al. 1981; Kubalakova et al. 2003). These are valuable resources and helpful in analytical and precision wheat breeding by manipulating specific chromosomes to achieve the wide ranging objectives.

Grain starch constitution in terms of amylose and amylopectin ratio of resulting flour is crucial for their suitability in specific type of food preparation. It is also a determinant of the digestibility in human gut. Diabetes mellitus, a disorder of carbohydrate metabolism, is a chronic disease prevalent globally. Approximately, 316 million people are suffering from diabetes worldwide (http://www.idf.org//2014). Managing diabetes and lifestyle ailments through drugs is highly cumbersome and thus dependence on staple diet modification is a vital approach. It has been reported that high amylose content plays a significant role in lowering glycemic index (Ankita et al. 2010).

In this study, we extended our previous work in which we suggested a major involvement of chromosomes 3A, 4B, 2D and 7D in determining grain yield in temperature dependent manner but a high precision temperature window was missing (Passricha et al. 2015). Keeping all the above-mentioned issues in mind, the present study was undertaken to $(i)$ evaluate selected wheat DCS lines for AGPase activity and various agro-physiological traits in determining yield; (ii) correlating yield impacting parameters with the specific temperature bracket; and (iii) evaluating selected wheat DCS lines for sugar and starch estimation. In this context, possible use of this approach for crop improvement has been also discussed.

\section{Materials and Methods}

\section{Plant materials}

From a stock of wheat DCS lines (specific chromosome of wheat variety C-591 substituted in the background of rest of Chinese Spring chromosomes), eight lines (3A, 6A, 1B, 2B, $4 \mathrm{~B}, 5 \mathrm{~B}, 2 \mathrm{D}$ and 7D) were selected on the basis of our previous analysis (Passricha et al. 2015). These selected lines were procured from Department of Genetics and Plant Breeding, CCSHAU, Hisar and were grown in a row of 1.5 meters each in 3 replications in randomized block design during rabi season of 2012-2013 and 2013-2014. At spike emergence, plants were tagged for sample collection at different days after anthesis (DAA).

\section{Biochemical parameters}

AGPase activity (nmol mg-1 $\mathrm{min}^{-1}$ ) at 14, 21 and 28 DAA in selected wheat DCS lines was assayed in the reverse direction by modified method of Kleczkowski et al. (1993) and 
the activity was associated with average temperature data (obtained from Department of Agricultural Meteorology, CCSHAU, Hisar) experienced by the wheat lines during particular duration of DAA. Total starch and amylose content were determined by phenolsulphuric acid (Dubois et al. 1951) and iodine method (Bates et al. 1943), respectively. Further, total soluble sugars and reducing sugars were estimated by phenol-sulphuric acid (Dubois et al. 1951) and Nelson method (1944) as modified by Somogyi (1945), respectively.

\section{Agro-physiological parameters}

Traits like days to anthesis (DTA), plant height (Ht), spikes per plant (S/P), spike length $(\mathrm{SL})$, grains per spike $(\mathrm{G} / \mathrm{S})$, grains weight per spike $(\mathrm{GW} / \mathrm{S})$, test grain weight $(\mathrm{TGW})$, grain yield $(\mathrm{GY})$, plant biomass $(\mathrm{PB})$, harvest index $(\mathrm{HI})$ and grain growth rate (GGR) were measured at 14, 21 and 28 DAA. The GGR was estimated for mean grain dry weight at 14, 21, 28 DAA and expressed as mg grain $^{-1}$ day $^{-1}$ (May and Van 1992).

\section{Statistical analysis}

The data collected during rabi season of 2012-2013 and 2013-2014 was subjected to analysis of variance, correlation and path analysis using online software package OPSTAT (http://14.139.232.166/opstat/default.asp). Correlation coefficient and path analyses was performed on pooled data of both the years. Path coefficient analysis was performed to estimate direct (effect of one variable over other variable) and indirect effects (effect of one variable over other through another variable) of yield contributing characters (predictor variables) on grain yield (response variable) per plant using phenotypic correlation (Panse and Sukhatme 1967).

\section{Results}

\section{Biochemical parameters}

Wheat developing grains' AGPase activity and its association with temperature

The AGPase activity at 14, 21 and 28 DAA revealed four different patterns of activity during rabi season of 2012-2013 and 2013-2014, though these were not same: (i) initially low and getting high over subsequent phases (7D and CS in 2012-2013 and 5B in 2013-2014); (ii) Initially high and getting low over subsequent phases (6A and 2D in 2012-13 and 2B in 2013-14); (iii) initially low, getting high and then moderate in later phases (3A, 5B and C-591 in 2012-13 and 1B, 7D and CS in 2013-14); and (iv) initially high, getting low and then moderate in later phases (1B, 2B and 4B in 2012-2013 and 3A, 6A, 4B, 2D and C-591 in 2013-2014). However, the maximum level of AGPase activity for each line was associated with a specific temperature range. Our data pointed to the fact that maximum AGPase enzyme activity of DCS line 3A was detected in temperature range of $22.0-26.5^{\circ} \mathrm{C}(445)$. Similarly, the maximum AGPase activity of DCS lines 6A, 


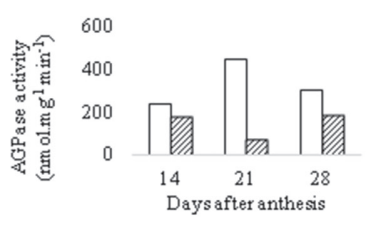

$3 \mathrm{~A}$

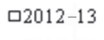

๒2013-14

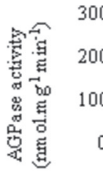

300

0

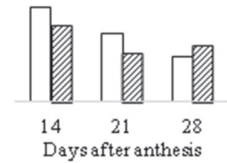

$6 \mathrm{~A}$

$1 B$

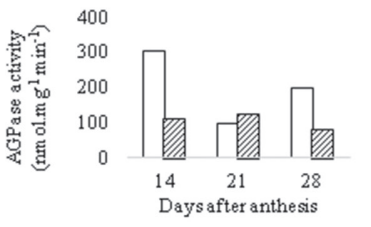

口2012-13

घ2013-14

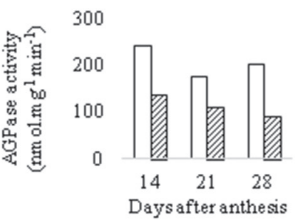

2B

व2012-13

๑2013-14

4B
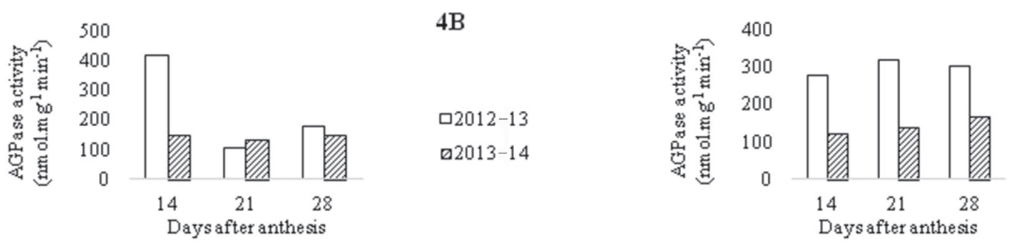

$5 \mathrm{~B}$

ㅁ2012-13

๑2013-14

$2 \mathrm{D}$

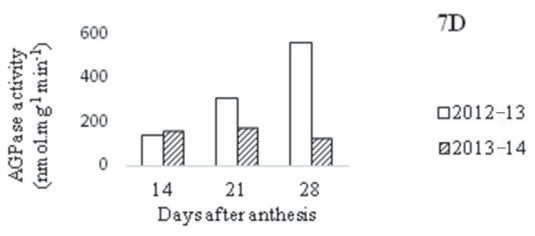

Figure 1. Comparative AGPase activity $\left(\mathrm{nmol} \mathrm{mg} \mathrm{min}^{-1}\right.$ ) of wheat lines, 3A, 6A, 1B, 2B, 4B, 5B, 2D and 7D at 14, 21 and 28 days after anthesis (DAA) during 2012-2013 and 2013-2014

$1 \mathrm{~B}, 2 \mathrm{~B}, 4 \mathrm{~B}, 5 \mathrm{~B}, 2 \mathrm{D}$ and $7 \mathrm{D}$ was in temperature range of $19.0-24.5^{\circ} \mathrm{C}(220), 20.1-24.5$ ${ }^{\circ} \mathrm{C}(305), 20.1-24.5^{\circ} \mathrm{C}(240), 19.0-24.5^{\circ} \mathrm{C}(420), 19.0-24.5^{\circ} \mathrm{C}(320), 20.1-24.5^{\circ} \mathrm{C}$ (240) and $24.9-26.5^{\circ} \mathrm{C}(560)$, respectively (Fig. 1, Table S1*).

\section{Starch and sugar estimation}

The quality of starchy foods is influenced by amylose-to-amylopectin ratio. The genotypes with elevated amylose content contains higher levels of resistant starch (RS) resulting in lower postprandial glycaemic responses (Hallstrom et al. 2011). In the present study, among selected DCS lines, the maximum value for total starch and amylopectin was measured in DCS line 3A (902.32 mg/g and $879.62 \mathrm{mg} / \mathrm{g}$, respectively) whereas the maximum value for total amylose was determined in DCS line $2 \mathrm{D}(22.76 \mathrm{mg} / \mathrm{g})$. Further, the minimum value for total starch, amylose and amylopectin was measured in DCS line 5B (407.62 mg/g), 3A (22.7 mg/g) and 7D (420.60 mg/g), respectively. The average

*Further details about the Electronic Supplementary Material (ESM) can be found at the end of the article. 


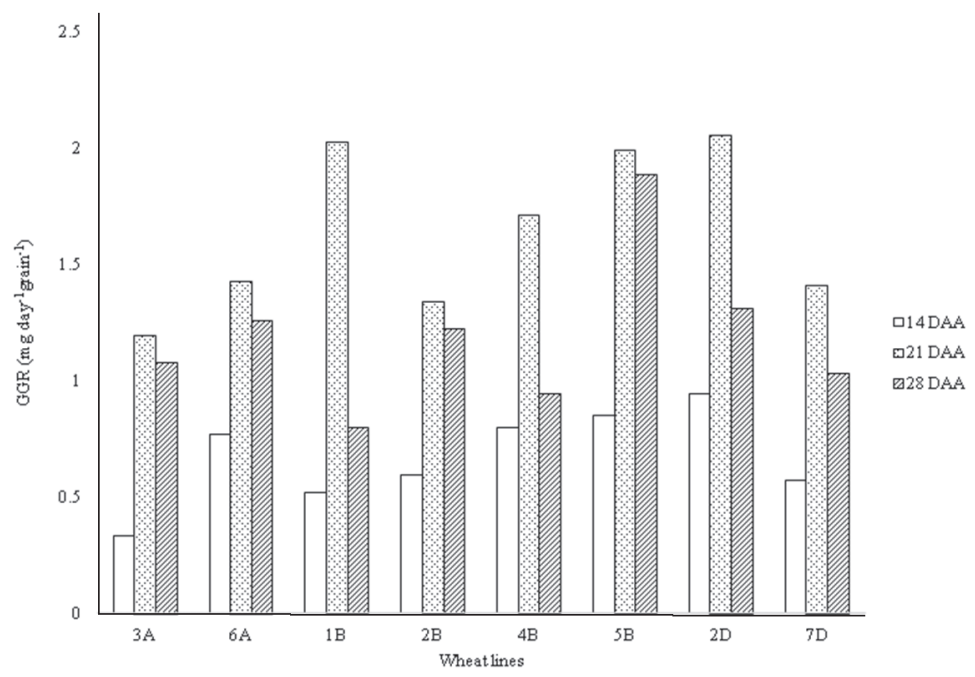

Figure 2. Grain growth rate (GGR) $\left(\mathrm{mg} \mathrm{day}^{-1}\right.$ grain $\left.^{-1}\right)$ at 14,21 and 28 days after anthesis (DAA) during 2013-2014

amount of total starch, amylose and amylopectin was estimated to be 540.81, 24.95 and $515.86 \mathrm{mg} / \mathrm{g}$, respectively, with value ranged from $407.62-902.32 \mathrm{mg} / \mathrm{g}$ for total starch, 22.7-29.81 mg/g for amylose and 384.15-879.62 mg/g for amylopectin (Fig. 2, Table S2). These finding showed that DCS line 2D is the most promising for developing genotypes with high amylose content. The maximum value for total soluble sugar and nonreducing sugar was measured in DCS line 6A $(83.33 \mathrm{mg} / \mathrm{g}$ and $69.67 \mathrm{mg} / \mathrm{g}$, respectively) whereas the estimated maximum value for reducing sugar was in DCS line 1B (17.37 $\mathrm{mg} / \mathrm{g})$. Further, the minimum value for total soluble sugar, reducing and non-reducing sugars was determined in DCS line 7D $(62.74 \mathrm{mg} / \mathrm{g}), 5 \mathrm{~B}(11.00 \mathrm{mg} / \mathrm{g})$ and 2B (45.63 $\mathrm{mg} / \mathrm{g})$, respectively. The average amount of total soluble sugar, reducing and non-reducing sugar was measured to be $68.75,13.91$ and $54.84 \mathrm{mg} / \mathrm{g}$, respectively, with value ranged from $62.74-83.33 \mathrm{mg} / \mathrm{g}$ for total soluble sugar, $11.00-17.37 \mathrm{mg} / \mathrm{g}$ for reducing sugar and 45.63-69.67 mg/g for non-reducing sugars, respectively (Table 1). These results indicated a non-linear relationship between sugar and starch. For instance, DCS line $3 \mathrm{~A}$ was found to have maximum amount of total sugar and minimum amount of total starch was also measured in this line.

\section{Agro-physiological parameters}

Large variability was observed among all the selected wheat DCS lines regarding agrophysiological traits studied during rabi season of 2012-2013 and 2013-2014. For instance, grain yield ranged from 3.27-6.01 g in 2012-2013 and 6.38-14.90 g in 20132014. Highest grain yield was reported in DCS line 2D in both the years (Tables S2 and S3). GGR at 14, 21 and 28 DAA showed two patterns of activity: $(i)$ initially low, getting 
Table 1. Starch $(\mathrm{mg} / \mathrm{g})$ and sugar $(\mathrm{mg} / \mathrm{g})$ content of wheat lines

\begin{tabular}{|c|c|c|c|c|c|c|}
\hline Wheat lines & Total starch & Amylose & Amylopectin & Total sugar & Reducing sugar & $\begin{array}{c}\text { Non-reducing } \\
\text { sugar }\end{array}$ \\
\hline 3A & 902.32 & 22.70 & 879.62 & 72.58 & 14.28 & 58.30 \\
\hline 6A & 570.17 & 26.28 & 543.89 & 83.33 & 13.64 & 69.67 \\
\hline 1B & 607.36 & 24.65 & 582.71 & 71.54 & 17.37 & 54.17 \\
\hline 2B & 542.32 & 24.03 & 518.29 & 62.91 & 17.28 & 45.63 \\
\hline 4B & 534.20 & 22.76 & 511.45 & 66.69 & 11.46 & 55.23 \\
\hline 5B & 407.62 & 23.47 & 384.15 & 66.05 & 11.00 & 55.05 \\
\hline 2D & 470.32 & 29.81 & 440.51 & 80.57 & 14.46 & 66.11 \\
\hline 7D & 448.26 & 27.66 & 420.60 & 62.74 & 14.36 & 48.38 \\
\hline CS & 365.81 & 20.45 & 345.36 & 56.29 & 15.64 & 40.65 \\
\hline C-591 & 559.74 & 27.66 & 532.08 & 64.84 & 9.63 & 55.21 \\
\hline Mean & 540.81 & 24.95 & 515.86 & 68.75 & 13.91 & 54.84 \\
\hline C.D. & 11.32 & 2.77 & - & 13.23 & 2.77 & - \\
\hline SE (m) & 3.85 & 0.94 & - & 4.49 & 0.94 & - \\
\hline SE (d) & 5.44 & 1.33 & - & 6.36 & 1.33 & - \\
\hline CV & 9.67 & 9.41 & - & 9.32 & 9.41 & - \\
\hline
\end{tabular}

$\mathrm{CD}$ - coefficient of deviation, SE (m) - standard error mean, SE (d) - standard error deviation, CV - coefficient of variance

high and then moderate in later stages (3A, 6A, 1B, 4B, 5B and 7D in 2012-2013 and 2013-2014 and 2B, 2D and CS in 2013-2014); and (ii) initially low and getting high over subsequent phases (2D, 2B, CS in 2012-2013 and C-591 in 2012-2013 and 2013-2014). These finding indicates that most of the wheat lines showed first pattern of GGR activity (Fig. 2, Table S4).

\section{Statistical analysis}

Mean sum of squares during both the years (2012-2013 and 2013-2014) was highly significant for all the traits studied under present study (Tables S5 and S6). These results indicating a large variation among all the DCS lines with respect to the traits studied. Significant positive correlation was found between: $(i)$ grain yield with spikes per plant, grains per spike, grain weight per spike and plant biomass; ( $i i)$ days to anthesis with plant height; (iii) spikes per plant with grains per spike; (iv) grains per spike with plant biomass; (v) grain weight per spike with test grain weight, GGR 14 and GGR 21; (vi) test grain weight with GGR 14, GGR 21 and GGR 28; (vii) harvest index with GGR 28; (viii) GGR 14 with GGR 21; and (ix) GGR 21 with GGR 28. Whereas, significant negative correlation was observed between: ( $i$ ) days to anthesis with harvest index and GGR 28; (ii) plant height with harvest index; and (iii) AGPase 14 with AGPase 21 (Table S7). 
Partitioning the variation by path analysis indicated that plant height, spikes/plant, spike length, grains per spike, test grain weight, harvest index, GGR at 28 DAA and AGPase activity at 14 DAA and 28 DAA had direct positive effect on grain yield. The maximum positive direct effect was shown by plant height (3.762) followed by test grain weight (3.305) and minimum effect was shown by AGPase activity at 14 DAA (0.162). The parameters: (i) spikes per plant; (ii) grains per spike; (iii) grain weight per spike; and (iv) plant biomass had significant positive correlation with grain yield. Hence, we focussed only on these traits during our analysis. Our data pointed to fact that though grains per spike had less direct effect (0.319) but impacting grain yield indirectly via AGPase 21 (1.273). Similarly, grain weight per spike and plant biomass had no direct effect but contributing to grain yield indirectly via test grain weight (2.031) and AGPase 21 (1.480 for grain weight per spike and 1.625 for plant biomass, respectively) (Table S8).

\section{Discussion}

The results of the present study revealed that AGPase enzyme of each DCS line worked in a strict temperature range and any deviation from this range was detrimental for its activity which in turn affected grain yield. AGPase enzyme activity in wheat developing grains at different DAA increased in all the wheat lines and reached their peaks but the maximum peak value and time was different in different wheat lines (Fig. 1).

In DCS line 2D, AGPase worked during initial stages of grain filling in a strict temperature range of $23 \pm 1.5^{\circ} \mathrm{C}$ and had maximum 1000 grains weight $(27.91 \mathrm{~g}$ in $2012-$ 2013 and $38.56 \mathrm{~g}$ in 2013-2014) and comparably high grains per spike (55.45 in 20122013 and 47.32 in 2013-2014) than other DCS lines (Tables S5 and S6), which are the major yield contributor. These results receive support from our previous findings (Passricha et al. 2015) where we reported chromosome $2 \mathrm{D}$ to be the major yield contributor. It may be possible that factors controlling AGPase on chromosome 2D are much more efficient towards starch biosynthesis than others. Huang et al. (2015) and Zhang et al. (2015) also reported QTL related to grain size on chromosome 2D. This wheat line may find place in future breeding program aimed for higher productivity. However, in the previous analysis, the AGPase activity pattern observed was initially low which consistently increased towards maturity in 2D line. Whereas, in the present study, a reverse trend is obtained for AGPase activity in this line which is high initially and consequently decreased over subsequent phases. These findings suggest a high influence of environmental conditions on AGPase activity. Because, it is one of the enzymes most profoundly affected by abiotic stress (Linebarger et al. 2005) resulting in changes in carbohydrate metabolism, particularly starch accumulation and starch-sucrose interconversion during grain filling periods (Yan et al. 2008). We also observed a deviation in the optimum temperature for AGPase activity in $2 \mathrm{D}$ line which ranged from $21.8-23.3{ }^{\circ} \mathrm{C}$ in the present study, while found at 23.5 to $26.2^{\circ} \mathrm{C}$ (during moderate temperature season) and even at $30.4{ }^{\circ} \mathrm{C}$ (terminal heat stress during high temperature season) in the former study (Passricha et al. 2015). These findings suggests that optimum temperature for enzyme activity is also influenced by other factors. Earlier workers have also reported the different optimum 
temperatures. For instance, Geigenberger et al. (1998) reported $25{ }^{\circ} \mathrm{C}$ as the optimum temperature for starch synthesis using radiolabels whereas Hurkman et al. (2003) reported AGPase to be the most sensitive to heat stress, particularly at temperatures above $34{ }^{\circ} \mathrm{C}$.

Further, in DCS line 5B, AGPase worked during the latter half of grain filling and had comparable 1000 grains weight (35.65 g in 2012-2013 and 27.76 g in 2013-2014) (Tables S5 and S6). It may be possible that AGPase of DCS line 5B has the ability to attain homeostasis. That's why being later starter, it had high grain yield per plant. Similarly, the effect of temperature on starch biosynthetic genes in wheat endosperm is also reported by Hurkman et al. (2003).

AGPase activity in each DCS line is contributing towards increasing grain weight or grain number, which is reflected in their grain yield. This suggested that determinants for AGPase expression are present over multiple chromosomes across the genome that are responsible for determining the activity of AGPase enzyme in developing wheat grains. For instance, AGPase enzyme activity in DCS lines 6A, 2B, 4B, 5B, 2D and 7D had contributed more towards grain weight than grain number per spike whereas in DCS lines $3 \mathrm{~A}$ and $1 \mathrm{~B}$, this enzyme's activity had contributed more towards grain number than grain weight.

On comparing activity patterns for AGPase and GGR, these were found to be different in different DCS lines. DCS line 3A showed higher GGR in comparison to AGPase activity; maximum amount of total starch along with minimum 1000 grains weight. This suggested that translocation mechanism is efficient in this line which is directing source towards sink. But, down-regulating genes may have drastic adverse effects in grain development of DCS line 3A. Similarly, DCS line 1B had higher GGR as compared to AGPase activity. Further, this line was found to be highly sensitive to environmental variations as there was considerable decrease in its test grain weight during second year (2013-2014). Test grain weight is one of the major indicators of grain yield as this line experiences less reproductive period.

The results of the present study were further substantiated by partitioning the effects by correlation coefficient and path analyses. Results of the present study receives support from findings of Hasna et al. (2011) where they found positive correlation of grain yield with spikes per plant, grains per spike, grain weight per spike and plant biomass. Shamsuddin (1987) also found direct relation of spikes per plant and grains per spike to grain yield in path analysis. Test grain weight was not found to be directly correlated with grain yield. It was found to be significantly correlated with GGR at all the three stages $(14,21$ and 28 DAA). Thus, grain growth rate at all the three stages contributed towards grain yield. However, we did not find a direct correlation between grain yield, GGR and AGPase. These results are not in agreement with Sheikh et al. (2010) where they observed strong positive and significant correlations among these traits. This may be due to different environmental conditions.

Small changes in the proportion of amylose-to-amylopectin have been extensively documented to not only alter starch functionality (Zeng et al. 1997), but also heavily influence the nutritional characteristics of starchy foods (Bird et al. 2006). This trait re- 
mains a focal point of starch research. A non-linear relationship was observed among sugar and starch content. For instance, total starch and amylose content was highest in DCS line 3A $(902.3 \mathrm{mg} / \mathrm{g})$ and line 2D $(29.81 \mathrm{mg} / \mathrm{g})$, respectively (Table S3). Whereas, DCS line 6A $(83.3 \mathrm{mg} / \mathrm{g})$ and line 1B $(17.4 \mathrm{mg} / \mathrm{g})$ were found to have highest content of total sugar and reducing sugar content (Table S4), respectively. In vitro studies on cereal genotypes with elevated amylose contents also showed a relationship between amylose content and amount of resistant starch formed during processing. Intake of food products rich in resistant starch shown to be associated with low postprandial glucose and insulin responses (Hallstrom et al. 2011). Therefore, DCS line 2D with highest amylose content and low digestibility flour may find place in future breeding program.

\section{References}

Ankita, M., Yenagi, N.B., Kasturiba, B. 2010. Designing of low glycaemic chapati of dicoccum wheat for the effective management of diabetes. Karnataka J. Agricul. Sci. 23:476-479.

Bates, F.L., French, D., Rundle, R.E. 1943. Amylose and amylopectin content of starches determined by their iodine complex formation. J. Am. Chem. Soc. 65:142-148.

Bird, A.R., Brown, I.L., Topping, D.L. 2006. Low and high amylose maize starches acetylated by a commercial or a laboratory process both deliver acetate to the large bowel of rats. Food Hydrocoll. 20:1135-1140.

Boehlein, S.K., Shaw, J.R., Stewart, J.D., Hannah, C. 2008. Heat stability and allosteric properties of the maize endosperm ADP-glucose pyrophosphorylase are intimately intertwined. Plant Physiol. 146:289-299.

Cornell, H. 2003. The chemistry and biochemistry of wheat. In: Cauvain, S.P. (ed.), Bread Making: Improving Quality. Woodhead Publishing Ltd. Sawston, UK. pp. 31-70.

Cross, J.M., Clancy, M., Shaw, J.R., Greene, T.W., Schmidt, R.R., Okita, T.W., Hannah, L.C. 2004. Both subunits of ADP-glucose pyrophosphorylase are regulatory. Plant Physiol. 135:137-144.

Dias, A.S., Lidon, C. 2009. Evaluation of grain filling rate and duration in bread and durum wheat, under heat stress after anthesis. J. Agron. Crop Sci. 195:137-147.

Dubois, M., Gilles, K., Hamilton, J.K., Rebers, P.A., Smith, F. 1951. A colorimetnc method for the determination of sugars. Nature 168(4265): 167.

Geigenberger, P., Hajirezaei, M., Geiger, M., Deiting, U., Sonnewald, U., Stitt, M. 1998. Overexpression of pyrophosphatase leads to increased sucrose degradation and starch synthesis, increased activities of enzymes for sucrose-starch interconversions, and increased levels of nucleotides in growing potato tubers. Planta 205:428-437.

Giroux, M.J. 1996. A single gene mutation that increases maize seed weight. Proc. Natl Acad. Sci. U.S.A. 93:5824-5829.

Hannah, L.C., Futch, B., Bing, J., Shaw, J.R., Boehlein, S., Stewart, J.D., Beiriger, R., Georgelis, N., Greene, T. 2012. A shrunken-2 transgene increases maize yield by acting in maternal tissues to increase the frequency of seed development. Plant Cell. 24:2352-2363.

Hallstrom, E., Sestili, F., Lafiandra, D., Bjorck, I., Ostman, E. 2011. A novel wheat variety with elevated content of amylose increases resistant starch formation and may beneficially influence glycaemia in healthy subjects. Food Nutr. Res. 55:7074.

Hasna, D., Ferdous, M.F., Mia, M.S., Shamsuddin, A.K.M. 2011. Study on genetic divergence and relationship between yield and yield contributing characters in spring wheat. J. Agroforest. Environ. 5:L121-124.

Huang, Y., Kong, Z., Wu, X., Cheng, R., Yu, D., Ma, Z. 2015. Characterization of three wheat grain weight QTLs that differentially affect kernel dimensions. Theor. Appl. Genet. 128:2437-2445.

Hurkman, W.J., McCue, K.F., Altenbach, S.B., Korn, A., Tanaka, C.K., Kotharia, K.M., Johnson, E.L., Bechtel, D.B., Wilson, J.D., Anderson, O.D., DuPont, F.M. 2003. Effect of temperature on expression of genes encoding enzymes for starch biosynthesis in developing wheat endosperm. Plant Sci. 164:873-881.

Joshi, B.C., Singh, D., Sawhney, R.N. 1981. Cytogenetics of Triticum macha. Cytologia 46:591-597. 
Kleczkowski, L.A., Villand, P., Luthi, E., Olsen, O., Preiss, J. 1993. Insensitivity of barley endosperm ADPglucose pyrophosphorylase to 3-phosphoglycerate and orthophosphate regulation. Plant Physiol. 101:179186.

Kubalakova, M., Valarik, M., Barto, J., Vrana, J., Cihalikova, J., Molnar-Lang, M., Dolezel, J. 2003. Analysis and sorting of rye (Secale cereale L.) chromosomes using flow cytometry. Genome 46:893-905.

Li, N., Zhang, S., Zhao, Y., Li, B., Zhang, J. 2011. Over-expression of AGPase genes enhances seed weight and starch content in transgenic maize. Planta 233:241-250.

Linebarger, C.R., Boehlein, S.K., Sewell, A.K., Shaw, J., Hannah, L.C. 2005. Heat stability of maize endosperm ADP-glucose pyrophosphorylase is enhanced by insertion of a cysteine in the $\mathrm{N}$ terminus of the small subunit. Plant Physiol. 139:1625-1634.

May, L., Van, D.A. 1992. Selection for early heading and correlated response in maturity of soft red winter wheat. Crop Sci. 32:47-51.

Nelson, N. 1944. A photometric adaptation of the Somogyi method for the determination of glucose. J. Biol. Chem. 153:375-380.

Panse, V.G., Sukhatme, P.V. 1967. Statistical Methods for Agricultural Workers, ICAR. New Delhi, India.

Passricha, N., Batra, R., Behl, R.K., Sikka, V.K. 2015. Differential and temperature dependent regulation of ADP-glucose pyrophosphorylase by specific chromosome in wheat grains. Cereal Res. Commun. 43:591603.

Saripalli, G., Gupta, P.K. 2015. AGPase: its role in crop productivity with emphasis on heat tolerance in cereals. Theor. Appl. Genet. 128:1893-1916.

Shamsuddin, A.K.M. 1987. Path analysis on bread wheat. Indian J. Agr. Sci. 57:47-49.

Sheikh, S., Sikka, V.K., Behl, R.K., Kumar, A. 2010. Grain growth rate and grain yield in relation to ADPglucose pyrophosphorylase activity in wheat (Triticum aestivum L. em. Thell) under normal and late sown conditions. Cereal Res. Commun. 38:589-599.

Somogyi, M. 1945. A new reagent for the determination of sugar. J. Biol. Chem. 160:61-69.

Stark, D.M., Timmerman, K.P., Barry, G.F., Preiss, J., Kishore, G.M. 1992. Regulation of the amount of starch in plant tissues by ADP glucose pyrophosphorylase. Science 258:287-292.

Yan, S.H., Yin, Y.P., Li, W.Y., Li, Y., Liang, T.B., Wu, Y.H., Geng, Q.H.,Wang, Z.L. 2008. Effect of high temperature after anthesis on starch formation of two wheat cultivars differing in heat tolerance. Acta Ecol. Sinica 28:6138-6147.

Zeng, M., Morris, C.F., Batey, I.L., Wrigley, C.W. 1997. Sources of variation for starch gelatinization, pasting and gelation properties in wheat. Cereal Chem. 74:63-71.

Zhang, G., Wang, Y., Guo, Y., Zhao, Y., Kong, F., Li, S. 2015. Characterization and mapping of QTLs on chromosome $2 \mathrm{D}$ for grain size and yield traits using a mutant line induced by EMS in wheat. The Crop J. $3: 135-144$

\section{Electronic Supplementary Material (ESM)}

Electronic Supplementary Material (ESM) associated with this article can be found at the website of CRC at http://www.akademiai.com/content/120427/

Electronic Supplementary Table S1. AGPase activity $\left(\mathrm{nmol} \mathrm{mg} \mathrm{min}^{-1}\right)$ at $14^{\text {th }}, 21^{\text {st }}$ and $28^{\text {th }}$ DAA along with the average temperature experienced by the wheat lines during grain development during 2012-2013 and 2013-2014

Electronic Supplementary Table S2. Agronomic performance of various traits under study during 2012-2013

Electronic Supplementary Table S3. Agronomic performance of various traits under study during 2013-2014

Electronic Supplementary Table S4. GGR $\left(\mathrm{mg}\right.$ day ${ }^{-1}$ grain $\left.^{-1}\right)$ at $14^{\text {th }}, 21^{\text {st }}$ and $28^{\text {th }}$ DAA during $2012-2013$ and 2013-2014 
Electronic Supplementary Table S5. Mean squares from ANOVA for wheat lines during 2012-2013 for various traits

Electronic Supplementary Table S6. Mean squares from ANOVA for wheat lines during 2013-2014 for various traits

Electronic Supplementary Table S7. Quantitative estimation and evaluation of different traits using correlation matrix during 2012-2013 and 2013-2014

Electronic Supplementary Table S8. Path analysis showing direct (diagonal bold values) and indirect effects of different traits on grain yield 